\title{
Controle de qualidade da droga vegetal e preparação do extrato de folhas de Passiflora edulis
}

\section{Herbal drug quality control and extract preparation of Passiflora edulis leaves}

Natália Pereira Trevisan ${ }^{1 *}$, Emilly Isabelli dos Santos Teodoro ${ }^{2}$, Clara Beatriz de Lima ${ }^{2}$, Naiara Cássia Gancedo ${ }^{2}$, Ana Paula Margioto Teston ${ }^{1}$, João Carlos Palazzo de Mello², Daniela Cristina de Medeiros Araújo ${ }^{1}$.

\section{RESUMO}

Objetivo: Realizar o controle de qualidade da droga vegetal e a preparação e avaliação da capacidade antioxidante do extrato bruto das folhas de Passiflora edulis. Método: Foram utilizadas as metodologias preconizadas na $6^{\mathbf{a}}$ edição da Farmacopeia Brasileira. Resultados: O teor de matéria estranha e umidade foram de $0,11 \%$ e $10,99 \%$, respectivamente, valores dentro do limite especificado pela Farmacopeia Brasileira. Já o teor de cinzas totais $(17,8 \%)$ ficou acima do limite máximo de $10 \%$. Quanto a determinação do índice de espuma, os valores foram inferiores a $1 \mathrm{~cm}$, estando de acordo com o especificado em monografia de P. edulis. A determinação do teor de flavonoides totais foi de 59,20\%, bem acima do teor mínimo de $15 \%$ estabelecido pela Farmacopeia Europeia. A produção do extrato bruto (EB) a partir da droga vegetal foi realizada pelo método de turbo extração, com rendimento $13,25 \%$. Em relação à análise de DPPH o EB apresentou $\mathrm{IC}_{50}$ de $314,0033 \mu \mathrm{g} / \mathrm{mL}$. Conclusão: a droga vegetal apresentou características de qualidade e o EB apresentou alta capacidade antioxidante pelo teste de DPPH, demonstrando potencial da amostra para utilização na produção de medicamentos e cosméticos.

Palavras Chaves: controle físico-químico; morfologia; flavonoides.

\begin{abstract}
Objective: To carry out the quality control of the plant drug and the preparation and evaluation of the antioxidant capacity of the crude extract of Passiflora edulis leaves. Method: The methodologies recommended in the 6th edition of the Brazilian Pharmacopoeia were used. Results: The foreign matter and moisture content was $0.11 \%$ and $10.99 \%$, respectively, values within the limit specified by the Brazilian Pharmacopoeia. The total ash content (17.8\%) was above the maximum limit of $10 \%$. As for the determination of the foam index, the values were less than $1 \mathrm{~cm}$, being in accordance with what was specified in the monograph of P. edulis. The determination of the total flavonoid content was 59,20\%, well above the $15 \%$ minimum content established by the European Pharmacopoeia. The production of the crude extract (EB) from the plant drug was carried out by the turbo extraction method, with a $13.25 \%$ yield. Regarding the DPPH analysis, the EB presented an $\mathrm{IC}_{50}$ of $314.0033 \mu \mathrm{g} / \mathrm{mL}$. Conclusion: the plant drug showed quality characteristics and the EB showed high antioxidant capacity by the DPPH test, demonstrating the potential of the sample for use in the production of medicines and cosmetics.
\end{abstract}

Keywords: Physical-Chemical Control; morphology; flavonoids.

\footnotetext{
${ }^{1}$ Centro Universitário Ingá - UNINGÁ. *E-mail: nataliatrevisan7@gmail.com

${ }^{2}$ Universidade Estadual de Maringá - UEM.
} 


\section{INTRODUÇÃO}

O maracujá, que pertence à família Passifloraceae Juss. ex Rousell, tem se tornado cada vez mais um objeto de estudo em decorrência de suas propriedades medicinais. Isso ocorre pela grande presença de compostos bioativos, principalmente polifenóis, responsáveis por vários efeitos farmacológicos, como: capacidade antioxidante, antiinflamatória e sedativa/calmante (SILVA et al., 2017; OLIVEIRA et al., 1998).

Os principais compostos presentes nas folhas de espécies de Passiflora são flavonoides, como a vitexina e orientina (MORAES, 1995). Os flavonoides são considerados uma classe de metabólito secundário e apresentam grande relevância para a indústria farmacêutica (OLIVEIRA et al., 1998; MELETTI; MAIA, 1999), e são responsáveis pelo efeito calmante, popularmente conhecido do maracujá. Além disso, as folhas de Passiflora são utilizadas na produção de fitoterápicos com ação ansiolítica, sedativa, diurética, analgésica, entre outras (MELETTI; MAIA, 1999; BERALDO; KATO, 2010).

Em relação ao gênero Passiflora, existem mais de 400 espécies conhecidas, sendo Passiflora edulis Sims a principal espécie cultivada no Brasil. P. edulis é popularmente chamada de maracujá-azedo, maracujá-amarelo, maracujá-liso, maracujá roxo e maracujá-do-mato (PIRES; SÃO JOSÉ; CONCEIÇÃO, 2011; BERALDO; KATO, 2008). O cultivo de P. edulis no Brasil tem relevância mundial, pois o país detém $70 \%$ do domínio da produção desta espécie. Isso representa quase a totalidade do volume comercializado mundialmente (BRUNCKNER et al., 2002; SILVA; PEIXOTO; JUNQUEIRA, 2001).

Para que uma espécie ou droga vegetal, como as folhas de Passiflora, sejam utilizadas como matéria-prima na produção de fitoterápicos pela indústria farmacêutica, é necessário a realização e determinação de parâmetros relacionados ao controle de qualidade do material vegetal. No Brasil, quem estabelece os parâmetros e análises para o controle de qualidade de espécies vegetais é a Farmacopeia Brasileira (ANVISA, 2019).

A determinação do teor das substâncias biologicamente ativas, garantem a pureza, autenticidade e integridade do material vegetal. Já os testes fitoquímicos, como a realização de técnicas cromatográficas, seja para a separação ou isolamento de substâncias, auxiliam a identificar as principais classes de metabólitos secundários presentes no vegetal (SOUZA et al., 2017). 
Portanto, para o uso seguro e eficiente das propriedades medicinais presentes nas folhas do maracujá, é preciso determinar a qualidade da matéria-prima. Devido a relevância da espécie $P$. edulis no país, o presente estudo objetivou realizar a caracterização botânica da droga vegetal, análises físico-químicas e fitoquímicas, preparação do extrato bruto e verificação do seu potencial antioxidante.

\section{MATERIAL E MÉTODOS}

\section{Coleta e preparo do material vegetal}

As etapas do estudo estão descritas no diagrama 1. As folhas de P. edulis foram coletadas nos dias 13 e 14 do mês de abril de 2021, no período da tarde, resultando em aproximadamente $10 \mathrm{~kg}$. As coletas foram realizadas mediante autorização no campus da Uningá, Maringá, Paraná, Brasil (2322'03"S 5153'57"W).

Diagrama 1. Roteiro metodológico

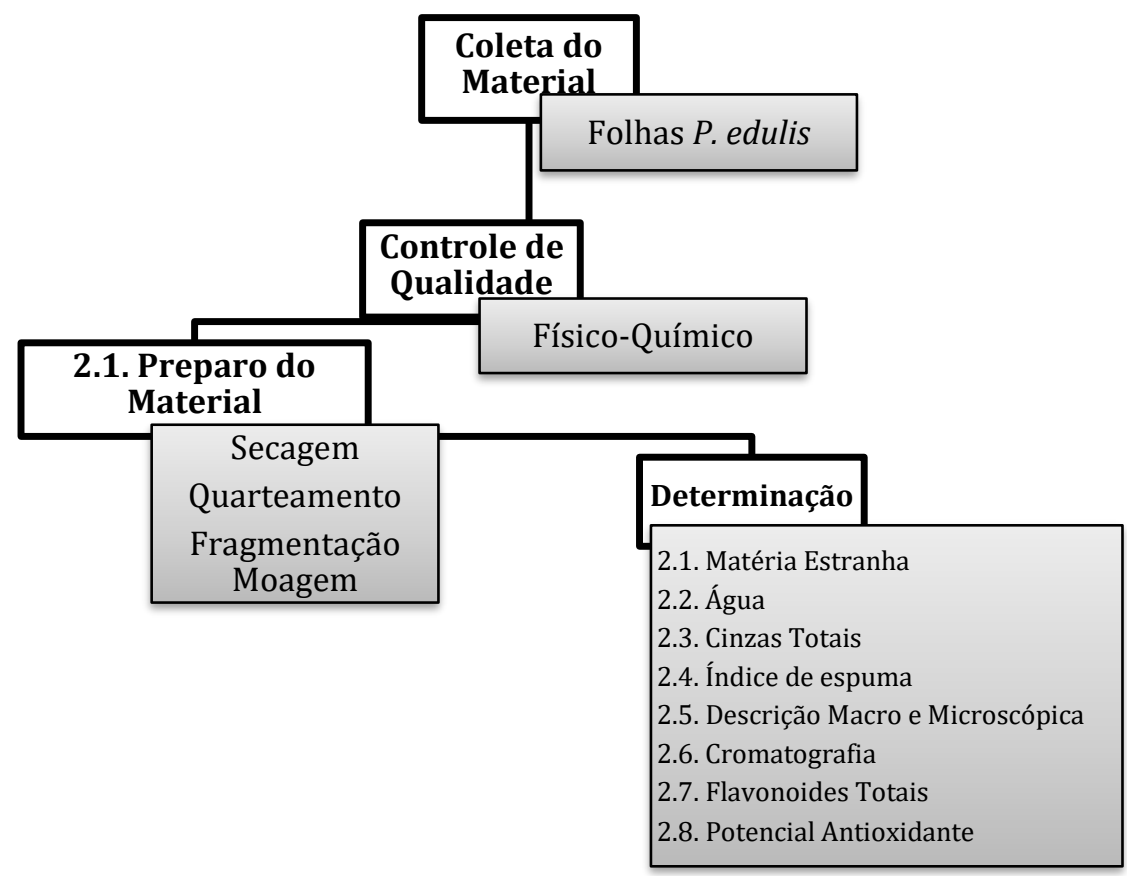

Controle de qualidade físico-químico da droga vegetal

\section{Preparo do material}


As folhas coletadas de $P$. edulis foram submetidas à secagem em estufa de ar circulante em condições controladas de temperatura à $36,0^{\circ} \mathrm{C}$ durante $72 \mathrm{~h}$. A amostra seca foi submetida ao processo de quarteamento e $250 \mathrm{~g}$ do farmacógeno foram reservados para a determinação de matéria estranha. O quarteamento é uma forma de garantir a redução do tamanho da amostra primária, mantendo a boa representatividade e evitando-se pulverização de grandes volumes (OLIVEIRA; AQUINO, 2007). O restante da droga vegetal foi pulverizado em moinho de martelos (Tigre, ASN6).

\subsection{Determinação de matéria estranha}

Uma camada fina da amostra ( $250 \mathrm{~g}$ ) foi espalhada sobre uma superfície plana. A matéria estranha, ou seja, qualquer material que não conste na descrição farmacopeica da espécie vegetal, foi manualmente removida, primeiramente a olho nu e depois com auxílio de lente de aumento (5 e 10 vezes). Após, o farmacógeno restante foi novamente pesado e descontado a diferença da amostra antes do processo, para determinar a porcentagem de matéria estranha (ANVISA, 2019).

\subsection{Perda por dessecação}

Para determinar a perda por dessecação foi utilizado o método de dessecação por balança com infravermelho (Ohaus, modelo MB35). Foi pesado cerca de $1 \mathrm{~g}$ da amostra, distribuída uniformemente no coletor. Em seguida, a amostra foi submetida à temperatura de $105^{\circ} \mathrm{C}$ pelo período de $45 \mathrm{~min}$. Esse processo foi realizado em triplicada e através da média o resultado foi expresso em perda de substâncias voláteis e/ou água residual (ANVISA, 2019).

\subsection{Determinação das cinzas totais}

As cinzas totais incluem tanto as fisiológicas quanto as não-fisiológicas. Foram utilizados cerca de $3 \mathrm{~g}$ da droga vegetal pulverizada, e transferidos para cadinhos previamente tarados. Em seguida foram incinerados em mufla (Solidsteel, modelo SSFM $6,7 \mathrm{~L})$, utilizando gradiente de temperatura $\left(30 \mathrm{~min}\right.$ a $200^{\circ} \mathrm{C}, 60 \mathrm{~min}$ a $400{ }^{\circ} \mathrm{C}$, e $90 \mathrm{~min}$ 
a $600{ }^{\circ} \mathrm{C}$ ), até toda parte orgânica ser eliminada. Aguardou-se o resfriamento em dessecador e realizou-se a pesagem. A análise foi realizada em quintuplicada e a porcentagem de cinzas totais foi calculada em relação à droga seca (ANVISA, 2019).

\subsection{Determinação do índice de espuma}

Iniciou-se com a pesagem exata de $1 \mathrm{~g}$ da amostra pulverizada, transferida para Erlenmeyer contendo $50 \mathrm{~mL}$ de água fervente. A amostra foi mantida em fervura por 30 min. Após foi resfriada, filtrada e completado com água o volume em balão volumétrico de $100 \mathrm{~mL}$. A amostra foi dividida em 10 tubos de ensaio com tampa, em séries sucessivas de 1 a $10 \mathrm{~mL}$. Após, cada tubo foi completado com água até alcançar $10 \mathrm{~mL}$, tampados e agitados, em movimentos verticais por $15 \mathrm{~s}$. O resultado foi expresso de acordo com a altura da espuma. (ANVISA, 2019).

\subsection{Descrição macroscópica e microscópica}

$\mathrm{Na}$ análise macroscópica foi realizada a identificação das folhas inteiras, observando o tamanho, cor, consistência, textura, e superfície foliar. Para identificação do odor foi colocado uma amostra em um recipiente de vidro e inalado devagar, repetidas vezes, e classificado a intensidade do odor (ANVISA, 2019).

Para a análise microscópica, as folhas de $P$. edulis foram seccionadas à mão livre com o auxílio de lâmina de barbear, descoradas com a solução de hipoclorito de sódio $30 \%$ e coradas com a dupla coloração azul de Astra e safranina (1:1, v/v). Em seguida, as secções foram montadas como lâminas semipermanentes em gelatina glicerinada e observadas em microscópio óptico (MO) (KRAUS; ARDUIN, 1997).

\subsection{Flavonoides totais}

Para a determinação do teor de flavonoides totais foram preparadas as soluções estoque, amostra e branco.

Para o preparo da solução estoque foram pesados $0,400 \mathrm{~g}$ do farmacógeno pulverizado e colocado em um balão de fundo redondo de $50 \mathrm{~mL}$. Adicionaram-se $20 \mathrm{~mL}$ de álcool etílico $50 \%$ (v/v) e a mistura foi mantida sob refluxo por $30 \mathrm{~min}$. Em seguida a 
amostra foi filtrada e $20 \mathrm{~mL}$ de álcool etílico $50 \%$ (v/v) foi adicionado, mantendo em refluxo por mais $30 \mathrm{~min}$. Filtrou-se novamente em papel filtro e o filtrado foi transferido para um balão volumétrico de $50 \mathrm{~mL}$, completado o volume com álcool etílico $50 \%$ (v/v) e homogeneizado (ANVISA, 2019). Esse processo foi realizado três vezes e calculado a umidade e o teor de flavonoides totais.

No preparo da solução amostra, $0,8 \mathrm{~mL}$ da solução estoque foram transferidos para balão volumétrico de $10 \mathrm{~mL}$. Adicionados $0,8 \mathrm{~mL}$ de cloreto de alumínio a $2 \%(\mathrm{p} / \mathrm{v})$ em álcool etílico $50 \%$ (v/v), completado o volume com mesmo solvente e homogeneizado. Para a solução branco, foram transferidos $0,8 \mathrm{~mL}$ da solução em estoque para um balão volumétrico de $10 \mathrm{~mL}$ e completado o volume com álcool etílico 50\% (v/v) e homogeneizado.

Após o preparo das soluções, foi determinada a absorvância em espectrofotômetro à 397 nm da solução branco para ajuste do zero e da solução amostra. Então realizado o cálculo do teor de flavonoides totais conforme a fórmula abaixo, considerando Teor de Flavonoide (TF), absorvância (A) e massa da amostra em gramas (m), expressos em apigenina, em percentual conforme a $6^{\mathbf{a}}$ edição da Farmacopeia Brasileira (ANVISA, 2019).

$\mathrm{TF}=\underline{\mathrm{A} \times 625}$
$\mathrm{~m} \times 365,3$

\section{Preparação do extrato bruto (EB)}

O extrato bruto (EB) foi produzido a partir das folhas secas moídas de P. edulis, empregando álcool $50{ }^{\circ} \mathrm{GL}$ como líquido extrator, na proporção de $10 \%$ (p/v) de droga vegetal, pelo método de turbo-extração, durante $20 \mathrm{~min}$, com intervalos de $5 \mathrm{~min}$ e temperatura inferior a $40{ }^{\circ} \mathrm{C}$. O extrato foi filtrado e o volume final ajustado. Após, o extrato foi concentrado em evaporador rotatório sob pressão reduzida, à temperatura de $40{ }^{\circ} \mathrm{C}$, até a eliminação completa do solvente orgânico, congelado em nitrogênio líquido e liofilizado. $\mathrm{O}$ extrato bruto foi acondicionado e armazenado em freezer a $-20^{\circ} \mathrm{C}$. 


\subsection{Avaliação do potencial antioxidante do EB por DPPH}

Foi pesado, exatamente cerca de $1 \mathrm{mg}$ de EB, diluído em metanol (solução mãe, $\mathrm{SM}, 1 \mathrm{mg} / \mathrm{mL}$ ). A partir da SM foram realizadas diluições seriadas em tubos eppendorf de 2,0 mL, e homogeneizadas em vórtex, alcançando as concentrações de $100 \mu \mathrm{g} / \mathrm{mL}$ até 1,5625 $\mu \mathrm{g} / \mathrm{mL}$. Após, foram diluídos $1,7 \mathrm{mg}$ de DPPH em $1700 \mu \mathrm{L}$ de metanol, resultando em uma solução a $65 \mu \mathrm{M}$. Foram aplicados $100 \mu \mathrm{L}$ de cada diluição seriada do extrato em placas de 96 poços (triplicata), e adicionaram-se $100 \mu \mathrm{L}$ da solução de DPPH. Foram realizados os controles: negativo (metanol e DPPH), positivo (quercetina e vitamina C) e branco (metanol). Os controles positivos, quercetina e vitamina $\mathrm{C}$, foram diluídos em metanol nas concentrações de 30 e $50 \mu \mathrm{g} / \mathrm{mL}$, respectivamente. A placa foi incubada à temperatura ambiente e ausência de luz por 30 min e realizada a leitura a $517 \mathrm{~nm}$ em leitora de microplacas (EPOCH 2) (RUFINO et al., 2007; SOUSA, et al., 2007).

\section{RESULTADOS E DISCUSSÃO}

A secagem dos $10 \mathrm{~kg}$ das folhas de $P$. edulis em estufa com circulação de ar forçada resultou em 2,2254 $\mathrm{kg}$ do farmacógeno. A secagem em estufa é um método que mantém os teores de macronutrientes e é eficiente na obtenção da matéria seca para as análises químicas (MARCANTE, 2010; GANCEDO, 2019).

Com as folhas secas foram realizadas as análises de controle de qualidade. Essas etapas servem para identificar e quantificar os marcadores, podendo fornecer informações mais exatas quanto à presença de materiais externos à planta (ANVISA, 2019).

O processo de identificação, caracterização e avaliação de uma droga vegetal, deve compreender a autenticidade, que busca realizar a comparação entre as características das folhas e do padrão da descrição farmacognóstica. Para isso, utiliza-se o processo visual (FARIAS, 2003). Assim, a análise das folhas de P. edulis estão descritas a seguir considerando seus aspectos macro e microscópicos.

As folhas de $P$. edulis apresentaram comprimento médio de 6-10 $\mathrm{cm}$ e largura média de 10-13 cm. Cor verde escuro a castanho, consistência maleável e fina, com superfície lisa, bordas levemente serrilhadas e odor característico. As folhas são hipoestomáticas, com estômatos do tipo paracítico, anisolítico e normocítico. Presença de tricomas tectores unicelulares na região da nervura central, diferente do observado em $P$. 
flavicarpa (WOSCH, 2015) e semelhante ao descrito para P. edulis na Farmacopeia Brasileira (2019).

As folhas apresentaram cutícula espessa, em secção transversal, e epiderme uniestratificada, parênquima paliçádico contendo poucos estratos celulares e parênquima esponjoso constituído por várias camadas celulares (Figura 1A). A nervura principal, em secção transversal, apresenta uma protuberância na face adaxial e a face abaxial é convexa. A epiderme apresenta tricomas tectores unicelulares, na região da protuberância. Células de colênquima interrompem o parênquima clorofiliano (Figura 1B). O sistema vascular é composto por quatro feixes vasculares, com a presença de drusas no floema (Figura 1C). O pecíolo, em secção transversal, apresenta dois lobos evidentes na face adaxial, com a presença de colênquima internamente à epiderme. Em cada um dos lobos estão presentes feixes vasculares, além de grupos de feixes vasculares dispostos em forma de anel na região central (Figura 1D).
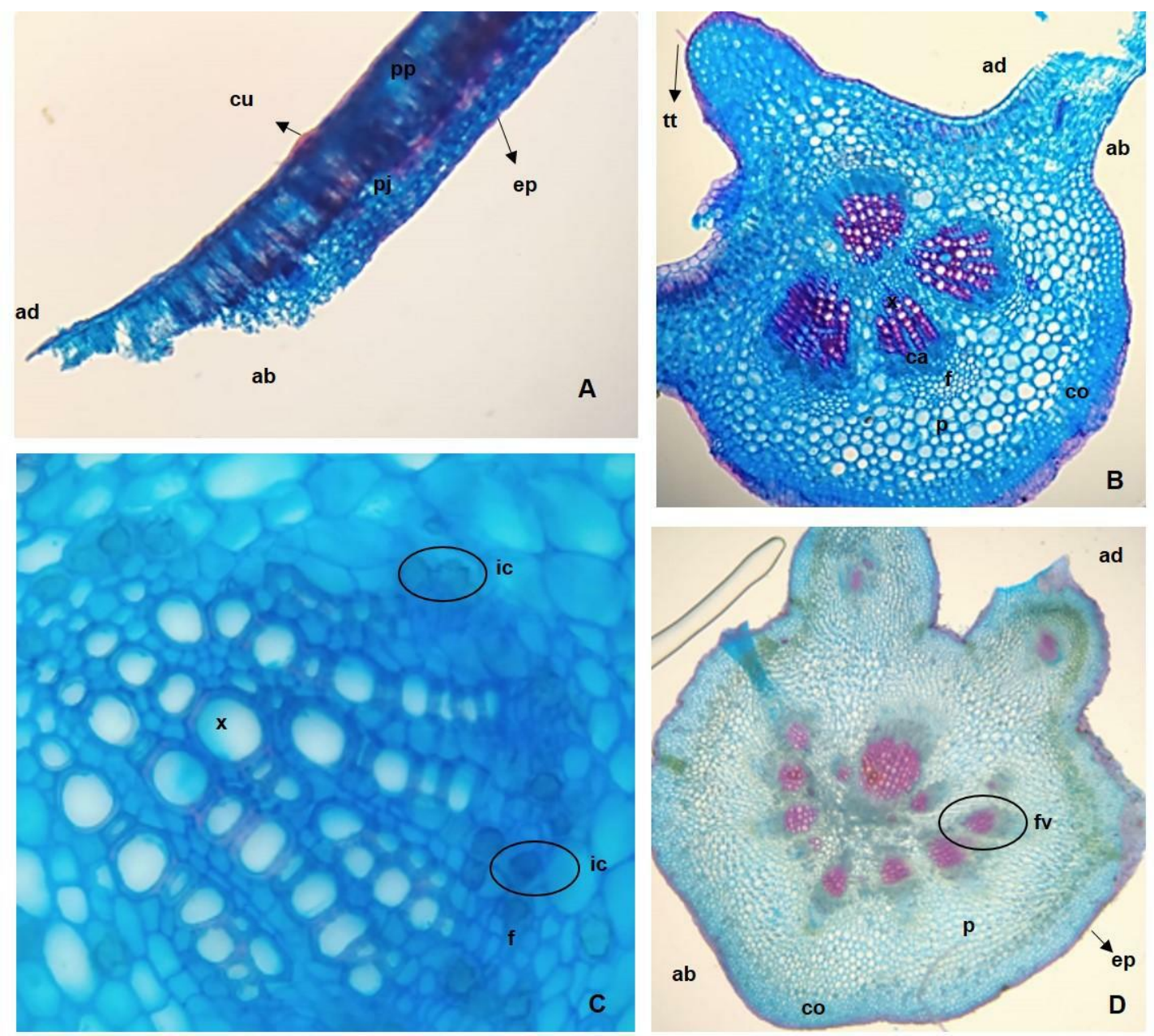

Figura 1. Aspecto microscópico das folhas e do pecíolo de Passiflora edulis. (A) Mesofilo em secção transversal. (B) Secção transversal da lâmina foliar e detalhe da 
nervura principal. (C) Detalhe da nervura central, em secção transversal, mostrando a presença de drusas na região do floema. (D) Aspecto geral do pecíolo em secção transversal. Face abaxial (ab); face adaxial (ad); câmbio (ca); colênquima (co); cutícula (cu); drusa (d); epiderme (ep); floema (f); feixe vascular (fv); inclusão celular (ic); parênquima paliçádico (pp); parênquima esponjoso (pj); xilema (x).

Com a análise de matéria estranha foram removidos da amostra inicial um total de $0,28 \mathrm{~g}$ de matéria estranha $(0,11 \%)$. Este valor está dentro do limite estabelecido pela Farmacopeia Brasileira (2019), que deve ser inferior a 2\% (p/p). Segundo a Farmacopeia Brasileira (2019), a matéria estranha pode ser classificada em três tipos principais, incluindo partes do órgão ou órgãos dos quais a droga vegetal provém, exceto os incluídos na definição e descrição da droga; quaisquer organismos, porções ou produtos de organismos não especificados em monografia; e impurezas de natureza mineral ou demais sujidades, não inerentes à droga vegetal (ANVISA, 2019).

Após retirada de matéria estranha, o montante total de folhas secas $(2,2254 \mathrm{~kg})$ foi submetido a moagem em moinho de martelos, resultando em 1,975 kg. Parte desta amostra foi submetida a análise do teor de umidade e determinação de cinzas totais, e os resultados podem ser observados na tabela 1 .

Tabela 1. Determinação da pureza das folhas de Passiflora edulis

\begin{tabular}{l|l}
\hline Ensaios & Resultados \pm DP $(\mathbf{C V \%})$ \\
\hline Determinação de água (\%) & $10,99 \pm 0,49(4,63 \%)$ \\
\hline Determinação de cinzas totais $(\%)$ & $17,8 \% \pm 0,61(3,44 \%)$ \\
\hline *DP. desvio padrão; CV: coeficiente de variação.
\end{tabular}

*DP: desvio padrão; CV: coeficiente de variação.

Considerando que o limite estabelecido pela Farmacopeia Brasileira (2019) para as folhas de $P$. edulis é de até $11,0 \%$ de água, a amostra encontra-se dentro do limite. Determinar o teor de água é importante, pois existem características que estão diretamente relacionadas, como o aroma, a cor, a densidade, e a conservação do produto (BERA; ALMEIRA, 2007). Esse valor permite considerar que o tempo de secagem foi suficiente e que o armazenamento foi realizado de forma correta, prevenindo a degradação do material vegetal (HUBINGER; SALGADO; MOREIRA, 2009; LIMA, 2019).

O teor de cinzas totais da amostra foi 17,8\%, ultrapassando o limite máximo de 10,0\% estabelecido na Farmacopeia Brasileira para as folhas de P. edulis (ANVISA, 2019). Como esta análise visa verificar impurezas inorgânicas não voláteis que podem 
estar presentes, este resultado indica a presença de materiais inorgânicos não voláteis (como por exemplo, pedra, terra ou areia), decorrente de alguma adversidade durante a coleta, higienização, ou preparo/processamento da amostra (SOUZA et al., 2017; GUZZO et al., 2015).

A análise do índice de espuma resultou espuma inferior a $1 \mathrm{~cm}$, encontrando-se dentro do parâmetro estabelecido pela Farmacopeia Brasileira (ANVISA, 2019).

A análise do teor de flavonoides totais resultou em 59,20\% $\pm 3,42(\mathrm{CV} \%=5,78)$. De acordo com a Farmacopeia Europeia, citada por Paris (2002), a espécie de Passiflora deve ter no mínimo $15 \%$ de flavonoides totais em sua matéria seca, para que possam ser utilizados pela indústria farmacêutica (FREITAS et al, 2007). Portanto, os resultados desse estudo estão dentro do parâmetro mínimo exigido. Considerando, que o teor do composto é utilizado como indicador de qualidade da planta, ao determinar sua atividade e isso impacta inclusive no valor de mercado da planta. Quanto maior o teor de flavonoides em suas folhas, maior seu preço, informação que reforça a importância desse tipo de estudo para a indústria farmacêutica, que investe em produtos de melhor qualidade (COHEN et al, 2008).

A produção do extrato bruto a partir da droga vegetal foi realizada pelo método de turbo extração, com rendimento $13,25 \%$. A avaliação do potencial antioxidante foi realizada utilizando o extrato bruto e os padrões quercetina e vitamina C. Os resultados podem ser observados na tabela 2 . A curva padrão foi preparada com uma solução de Trolox em diferentes concentrações.

Tabela 2. Avaliação antioxidante do extrato bruto de Passiflora edulis.

\begin{tabular}{l|c}
\hline \multicolumn{1}{c|}{ Amostra } & IC50 $(\boldsymbol{\mu g} / \mathbf{m L}, \mathbf{C V} \%$ \\
\hline Extrato Bruto de $\boldsymbol{P .}$ edulis & $314,0033 \pm 15,09(4,80)$ \\
Quercetina & $19,91 \pm 0,40(2,02)$ \\
Ácido ascórbico & $17,98 \pm 0,66(3,69)$ \\
& \\
\hline
\end{tabular}


Neste estudo obteve-se a informação que com $314,0033 \mu \mathrm{g} / \mathrm{mL}$ de extrato das folhas de P. edulis é possível reduzir 50\% do radical DPPH. Vieira (2013) também analisou as folhas de $P$. edulis, destacando sua capacidade antioxidante.

\section{CONCLUSÃO}

A maioria dos resultados encontraram-se dentro do padrão estabelecido pela Farmacopeia Brasileira e Europeia.

A descrição macro e microscópica e a ausência de matérias estranhas estão de acordo com a Farmacopeia Brasileira e identifica a espécie $P$. edulis.

Os teores de umidade, espuma e flavonoides totais encontram-se dentro do estabelecido na monografia da Farmacopeia Brasileira e Europeia.

O teor de cinzas totais, indicando a presença de materiais contaminantes, está fora do valor estabelecido pela Farmacopeia Brasileira, necessitando uma melhor avaliação no processo de coleta do farmacógeno.

\section{REFERÊNCIAS}

ANVISA. Farmacopeia Brasileira. vol. 1 e 2. $6^{\circ}$ ed. Agência Nacional de Vigilância Sanitária: Brasília, 2019. Disponível em: <http://portal.anvisa.gov.br/farmacopeiabrasileira>. Acessado em: 30 mar 2021.

ANVISA. Farmacopeia Brasileira, vol. 2. $5^{\text {a }}$ ed. Agência Nacional de Vigilância Sanitária: Brasília, 2010. Disponível em: $<$ https://www.gov.br/anvisa/ptbr/assuntos/farmacopeia/farmacopeia-brasileira/arquivos/8000json-file-1>. Acessado em: 30 mar 2021.

ALMEIDA, A. R. Caracterização morfoanatômica e química de Passiflora edulis Sims e Passiflora Setacea DC e seus mecanismos de cicatrização de feridas em ratos. Dissertação (mestrado em Farmácia) - Universidade de São Paulo. Orientador: BACCHI, E. M. São Paulo, 2014, 135f.

BERALDO, J; KATO, E. T. M. Morfoanatomia de folhas e caules de Passiflora edulis Sims, Passifloraceae. Rev. bras. farmacogn., Curitiba , v. 20, n. 2, 2010, p. 233-239.

BERA, A; ALMEIDA, L. B. M. Propriedades físico-químicas de amostras comerciais de mel com própolis do estado de São Paulo. Ciênc. Tecnol. Aliment., Campinas, v. 27, n. 1, 2007, p. 49-52. 
BORELLA, J. C. et al. Avaliação da espalhabilidade e do teor de flavonoides em forma farmacêutica semissólida contendo extratos de Calendula officinalis L. (Asteraceae).

Rev Ciênc Farm Básica Apl., v. 31, n. 2, 2010, p. 193-7.

COHEN, K. O. et al. Compostos funcionais na polpa dos frutos do híbrido de maracujazeiro azedo BRS Sol do Cerrado. Comunicado Técnico, v. 157, Planaltina: DF, 2008.

COSTA, M. G. Estudo químico de espécies brasileiras e colombianas do gênero Passiflora. Tese (doutorado em farmácia), 2013.

DUARTE, M. do R; LIMA, M. P. Análise farmacopeica de amostras de camomila. Visão Acadêmica, Curitiba, v. 4, n. 2, 2003.

FARIAS, M. R. Avaliação da qualidade de matéria-prima vegetal. In: SIMÕES, C.M.O. Farmacognosia: da planta ao medicamento, 5a. Ed. Revisada e ampliada, Porto Alegre/Florianópolis: Editora da UFRGS/Editora da UFSC, 2003.

FREITAS, M. S.M. et al. Flavonoides e composição mineral de folhas de maracujazeiro amarelo em função da posição da folha no ramo. Ciência Rural, v.37, n.6, 2007, p.1634-1639.

GANCEDO, N. C. Avaliação Etnofarmacológica da Casca Caulinar de Croton floribundus. Dissertação de mestrado. Programa de Pós-Graduação em Ciências Farmacêuticas. Universidade Estadual de Maringá, 2019.

GUIZZO, P. L. et al. Controle de Qualidade e triagem fitoquímica da droga vegetal das folhas de Morus nigra L. (MORACEAE). Rev Ciênc Farm Básica Apl., v. 36, n. 2, 2015, p. 259-265.

HUBINGER, S. Z; SALGADO, H. R. N; MOREIRA, R. R. D. Controles físico, físicoquímico, químico e microbiológicos do frutos de Dimorphandra molli. Revista Brasileira de Farmacognosia, v. 19, n. 3, 2009, p. 690-6.

LIMA, C. B. Desenvolvimento e controle de qualidade de xampu contendo extrato de Guazuma ulmifolia. Trabalho de conclusão do curso de farmácia - Universidade Estadual de Maringá, orientação Mello, J. C. P e ARAÚJO, D. C. M. Maringá, 2019.

MARCANTE, N. C. et al. Determinação da matéria seca e teores de macronutrientes em folhas de frutíferas usando diferentes métodos de secagem. Cienc. Rural, Santa Maria, v. 40, n. 11,2010 , p. $2398-2401$.

MELETTI, L.M.M; MAIA, M.L. Maracujá: produção e comercialização. Boletim Técnico Instituto Agronômico Estado de São Paulo, Campinas, v. 181, 1999, p. 1-62.

OLIVEIRA, M. L. M; AQUINO, J. A. Amostragem. In: Tratamento de Minérios: Práticas Laboratoriais - CETEM/MCT. Org: SAMPAIO, J. A. (Ed.); FRANÇA, S. C. A. (Ed.); BRAGA, P. F. A. Rio de Janeiro: CETEM, 2007. 570p.

OLIVEIRA, F. et al. Farmacognosia. 1. ed. Editora Atheneu, São Paulo, 1998. 
PARIS, F. de et al. Pharmacochemical study of aqueous extracts of Passilfora alata Drynder and Passiflora edulis Sims. Acta Farm Bonaerense, v.21, n.1, 2002, p. 5-8.

PIRES, M. M; SÃO JOSÉ, A. R.; CONCEIÇÃO, A.O. Maracujá : avanços tecnológicos e sustentabilidade. Ilhéus: Editus, 2011. 237p.

RUFINO, M.S.M et al. Determinação da atividade antioxidante total em frutas pela captura do radical livre DPPH. Comunicado Técnico Embrapa, v. 127, nº 1, 2007. SCORZA, L. C. T. Crescimento de gravinhas e identificação de genes potenciais diferenciadores de órgãos e meristemas em Passiflora edulis (passiflorácea). Tese (doutorado) - Universidade Estadual de Campinas, 2015.

SILVA, C. I, et al. Extração de compostos bioativos de folhas de maracujá-amarelo (Passiflora edulis Sims). XII Congresso Brasileiro de Engenharia Química em Iniciação Científica. UFSCar - São Carlos: SP, 16 a 19 de Julho de 2017.

SILVA, R. P; PEIXOTO, José Ricardo; JUNQUEIRA, Nilton Tadeu Vilela. Influência de diversos substratos no desenvolvimento de mudas de maracujazeiro azedo (Passiflora edulis Sims f. flavicarpa DEG). Rev. Bras. Frutic., Jaboticabal, v. 23, n. 2, p. 377-381, 2001.

SILVEIRA, A. C. M. Caracterização fitoquímica e avaliação da atividade antioxidante de materiais obtidos in vitro de Pass

iflora suberosa L. Dissertação (Mestrado em Biologia Vegetal) - Universidade do Estado do Rio de Janeiro, 2019, 90f.

SOUSA, C.M.M. et al. Fenóis totais e atividade antioxidante de cinco plantas medicinais. Química Nova, v. 30, n. 2, 2007, p. 351-5.

TOMÁS - BARBERÁN, F., EESPÍN, J. C. Phenolic compounds and related enzymes as determinants of quality of ruits and vegetables. J. Sci. Food Agric. v.81, p. 853-876, 2001.

VASCO, C.; RUALES, J., KAMAL-ELDIN, A. total phenolic compounds and antioxidant capacities of major fruits from Ecuador. Food Chem. v. 111, 2008, p. 816823.

VIEIRA, G. P. Compostos fenólicos, capacidade antioxidante e alcaloides em folhas e frutos (pericarpo, polpa e sementes) de Passiflora spp. Dissertação (mestrado em farmácia) - Universidade de São Paulo. São Paulo, 2013, 81p.

WOSCH, L. Estudo comparativo do perfil morfoanatômico e cromatográfico de folhas de Passiflora L., Passifloraceae. Dissertação (mestrado) - Universidade Federal do Paraná, 2015. 